\title{
The Importance of Prescribing Exercise Programs in Gyms
}

João Paulo da Silva Maciel ${ }^{1}$ Thiago Cabral de Souza ${ }^{2}$ Raphael Rodrigues Dias ${ }^{3}$ Elizabeth Alves Silva ${ }^{4}$

\begin{abstract}
This study evaluated the key indicators for prescribing exercise programs in gyms in the city of Barbalha - CE. It was a descriptive field study with 150 subjects, half men and half women. The results showed morphological changes in the main body segments. As for the purpose of the physical exercises, the main motivation was aesthetics. Few subjects reported doing the practice seeking a muscle reorganization.
\end{abstract}

Keywords: Prescription for exercise. Postural changes. Fitness Centers.

\section{Introduction}

Currently the exercise prescription patterns have been, in most cases, based on the frequency, intensity, duration and type of physical activity. However, it should be guided and properly moderate, similarly, provide a diagnosis involving since the anamnese of the history of diseases, along with an analysis of posture to the application of the sequence of physical tests, in order to adjust in a way more specific and individual, a physical training program. In this context, it is necessary that there is a sequence in this assessment series applied in a logical and coherent manner, in which a step of each stage should precede the other, following a hierarchy, to form a structure of exercises adopted in the training program.

\footnotetext{
${ }^{1}$ Graduate Degree in Physical Education from the School Leão Sampaio.

${ }^{2}$ Degree in Physical Education at the University Center UNILEÃO, North Ceará, Juazeiro do Norte. Technical Coordinator and Director of the School of Soccer Cruise Base Sport Club Minas Gerais core Juazeiro do Norte, the Cariri Cruise. Graduate student in Exercise Physiology and Special Groups in the University Center UNILEÃO. E-mail: cabral.10@gmail.com.

${ }^{3}$ Undergraduate in Physical Education from the Integrated Faculties of Cruise - FIC, São Paulo, Brasil. E-mail: rodriguesdiasraphael@gmail.com;

${ }^{4}$ Undergraduate Education from the State University of Vale do Acaraú, UEVA-CE, Brazil. Degree in Business Administration from the State University of Vale do Acaraú, UEVA-CE, Brazil. Specialization in Portuguese and Art Education for the Regional University of Cariri, URCA, Brazil. E-mail: elizabethalvessilva@gmail.com.
} 
Therefore and in this perspective, it is considered that an analysis of body segments to verify morphological changes is fundamental in the search for harmony between them. This aspect interfere in the best physical performances that are associated with good posture, whether in daily movements or in the execution of the exercise, static or dynamic.

According to Tribastone (2001), the posture relates to the optimized position maintained with automatic and spontaneous characteristic of an organism in perfect harmony with the gravitational force and biased to move from rest state to the moving state.

In gyms, samplings analysis in the diagnostic evaluation have been widely disseminated, as prescription form, adequation, monitoring and control in the application of exercises that can affect the assessed in certain injuries while performing movements, as may favor the limitations arising from changes.

In a sociological study, Pieron (2004) points out that, since the '70s, forced modernization of the countryside and the biased and exclusionary development has been leading to changes in the profile of life quality in rural and urban populations, reflecting in large social, cultural and economic transformations.

Based on the foregoing and aware of evidence that modern man uses less and less of their physical capabilities and that this fact is decisive in poor quality of life and the acquisition of several chronic diseases, the present study aims to evaluate quality of life, prevalence of overweight and postural changes to prescribing physical exercise program in gyms in the Barbalha municipality in the Ceara state.

In this context this research highlights the following question: how progress the quality of life of physical activity practitioners in gyms and what the prevalence of postural changes in the diagnostic evaluation for prescription and practice of Physical Training Program in the city of Barbalha in this Ceará?

\section{Materials and Methods}

The referent study classifies as an analysis of the results of a descriptive, quantitative, field and transversal study.

The population for this study was composed of individuals who were beginners at programs of physical activity in gyms in the city of Barbalha Ceará state. The sample 4 
consisted of 150 individuals, 75 men and 75 women, selected by simple random probabilistic method by conglomerate, with a mean age of $29.24+\ldots 12.70$ years, who enrolled in a health club to start an oriented program of exercise training. Thus it was obtained for the sample size a score that used the calculations for finite population with $\mathrm{p}=50 \%$ and the estimation error of $5 \%$, confidence level indicated $95 \%$.

For this study the independent variables were: sex, age (years), body weight $(\mathrm{kg})$ and height (m) and dependent variables: body mass index (BMI), waist to hip ratio (WHR), and observation of changes in body segments anterior, and posterior through the profile (latero lateral). Thus the research instruments and their functions are described in Table 01

Table 01. Instruments of research for data collection and function of samples

\begin{tabular}{c|c}
\hline Used Instruments & Instrumental Functions \\
\hline Anamnesis data sheet & Analysis for the research group \\
Digital scale Camry & Assess body mass \\
Portable stadiometer $(\mathbf{2 0 0} \mathbf{~ c m})$ Sanny & Assess height for body mass \\
Metric tape & Measure circumferences waist/hip \\
Wall & Project the received image \\
Table & Support the overhead projector \\
Overhead projector & Project the image on the wall \\
Transparency (simetograph) & Demarcate the body segments \\
\hline
\end{tabular}

Source: research 2014

The procedures went according to the provisions for compliance and fulfillment of Human Research, stated in Resolution 446/12. The studies were conducted from the evaluation of scheduling and time by the analyzed subject and soon after was given a free and informed consent of the National Health Council for due signature.

Initially, there was a brief inquiry and exposure of the real objectives of the research to analyzed and evaluated individuals and then there was an agency for the person to stay closer to nudity,meaning, speedo for boys and girls in bikini. The position of the measured gave the following way up and back (posterior view) and so requested that it undertake a small nearby natural walk playing a round trip within 10 meters multiple times to analysis segments of the feet, knees and scoliosis in dynamic and static movement.

Soon after there was the maneuver Adams (trunk flexion) with demarcation of the apophyses of the vertebrae with dermographic pen and placed it evaluated side (profile) for analysis of kyphosis and lordosis, knees, abdomen and shoulder girdle. Continuity was given to the analysis by the previous vision for the shoulder asymmetry, pelvis and head. And soon 
after we move to getting the weight and height measurements for analysis of body mass and also measures anthropometric waist circumference and hip.

Data from this study will be analyzed and the information will be tabulated according to descriptive statistics, so the results will be distributed through frequency using SPSS 16.0 (Descriptive Statistics Program). Subjected to analysis of cumulative frequency, relative percentage and cumulative percentage. The data were presented in frequency tables from Word for Windows software from Microsoft Office 2007.

\section{Results}

This study results the following values in cumulative frequency, relative and accumulated percentage of the variable age for male and female groups.

Table 02. cumulative frequency, relative percentage and cumulative percentage of variable - age group for females and male $(\mathrm{N}=150)$.

Table 02 provides the percentage of frequency data relative and cumulative percentage.

*Freq. = Frequency. $* \mathrm{~N}=$ Quantity

Source: research 2014

\begin{tabular}{c|cc|cc|cc}
\hline Age & \multicolumn{2}{|c}{ Freq. N=150 } & \multicolumn{2}{c}{ \% Relative } & \multicolumn{2}{c}{ \% Cumulative } \\
\hline & Fen & Mas. & Fem. & Mas. & Fem. & Mas. \\
& & & & & & \\
$\mathbf{1 7}$ a 20 & 15 & 17 & 10,0 & 11,3 & 15,0 & 17,0 \\
$\mathbf{2 1}$ a 23 & 17 & 13 & 11,3 & 8,7 & 32,0 & 30,0 \\
$\mathbf{2 4}$ a 30 & 15 & 14 & 10,0 & 9,3 & 47,0 & 44,0 \\
$\mathbf{3 1}$ a 40 & 15 & 13 & 10,0 & 8,7 & 62,0 & 57,0 \\
$\mathbf{4 1}$ a 50 & 06 & 07 & 4,0 & 4,7 & 68,0 & 64,0 \\
$\mathbf{5 1}$ a 60 & 05 & 07 & 3,3 & 4,7 & 73,0 & 71,0 \\
61 a 70 & 02 & 04 & 1,3 & 2,7 & 75,0 & 75,0 \\
Total & 75 & 75 & 50,0 & 50,0 & ---- & --- \\
\hline
\end{tabular}


Among men, it can be seen that the percentage frequency concerning the results were (11.3\%) aged between 17 and 20 years (8.7\%) aged between 21 and 23 years (9.3\%) with aged between 24 and 30 years (8.7\%) aged between 31 and 40 years (4.7\%) aged between 41 and 50 years (4.7\%) aged between 51 and 60 years (2.7\%) aged between 61 and 70 years.

Among women, it can be seen that the results were (10.0\%) aged between 17 and 20 years $(11.3 \%)$ aged between 21 and 23 years (10.0\%) aged 24 and 30 years (10.0\%) aged between 31 and 40 years (4.0\%) aged between 41 and 50 years (3.3\%) aged between 51 and 60 years $(1.3 \%)$ aged between 61 and 70 years. It was observed that the prevalent age group in the demand for gyms is between 18 and 29 years for both genders, followed by the range $30-45$ years.

Table 03. cumulative frequency, relative percentage and cumulative percentage of the analysis of body segment - Feet and Knees, for sex Male $(\mathbf{N}=75)$.

\begin{tabular}{c|c|c|c|c}
\hline Gender & Segment & Freq. $\mathbf{N}=\mathbf{7 5}$ & \% Relative & \% Cumulative \\
\hline \multirow{5}{*}{ Masculine } & Symmetrical & 24 & 16,0 & 24 \\
& Flat & 08 & 5,3 & 32 \\
& Valgus & 09 & 6,0 & 41 \\
& Varus & 15 & 10,0 & 56 \\
& Abduct & 10 & 6,7 & 66 \\
& Adduct & 04 & 2,7 & 70 \\
& Cavus & 05 & 3,3 & 75 \\
& Total & 75 & 50,0 & --- \\
\hline
\end{tabular}

$*$ Freq. $=$ Frequency $-* \mathrm{~N}=\mathrm{Quantity}$

Source: research 2014

Table 03 provides cumulative frequency data relative and cumulative percentage percentage. In men it can be seen that the percentage frequency on the results was that (16\%) are with feet and knees symmetrical, ie, normal and (5.3\%) flat feet, (6.0\%) knee valgus $(10.0 \%)$ varus knees $(6.7 \%)$ Abduct feet, $(2.7 \%)$ adduct feet $(3.3 \%)$ cavus feet. 
Table 04. cumulative frequency, relative percentage and cumulative percentage of the analysis of body segment - Feet and Knees, for sex Female $(N=75)$.

\begin{tabular}{ccrrr}
\hline Gender & Segment/Plan & Freq. N=75 & \% Relative & \% Cumulative \\
\hline \multirow{5}{*}{ Fem } & Symmetrical & 14 & 9,3 & 14 \\
& Flat & 11 & 7,3 & 25 \\
& Valgus & 16 & 10,7 & 41 \\
& Varus & 06 & 4,0 & 77 \\
& Abduct & 10 & 6,7 & 57 \\
& Adduct & 18 & 12,0 & 75 \\
& Cavus & 75 & 50,0 & ----- \\
\hline
\end{tabular}

*Freq. $=$ Frequency $-* \mathrm{~N}=\mathrm{Quantity}$

Source: research 2014

Table 04 comprises accumulated data on frequency and percentage cumulative percentage. Among women it can be seen that with respect to percentage of frequency on the results was that $(9.3 \%)$ are with feet and knees symmetrical, ie, normal, $(7.3 \%)$ flat feet, $(10.7$ $\%)$ valgus knees, $(4.0 \%)$ varus knees, $(6.7 \%)$ Abduct feet, $(12.0 \%)$ cavus feet.

Table 05. cumulative frequency, relative percentage and cumulative percentage of the analysis of the male-pathology scoliosis $(N=75)$.

\begin{tabular}{ccccc}
\hline Gender & Segments/Plan & Freq. $\mathbf{N = 7 5}$ & \% Relative & \% Cumulative \\
\hline & Absent & 18 & 12,0 & \\
& Simple Thorac. Right & 20 & 13,3 & 38 \\
\multirow{4}{*}{ Mas. } & Simple Thorac. Left & 14 & 9,3 & 52 \\
& Simple Lomb. Left. & 11 & 7,3 & 63 \\
& Thorac. S-shape - R/L & 07 & 4,7 & 70 \\
& Lumb. S-shape - R/L & 05 & 3,3 & 75 \\
& Total & 75 & 50,0 & ----- \\
\hline
\end{tabular}

*Freq. $=$ Frequency $-* \mathrm{~N}=\mathrm{Quantity}$

Source: research 2014

In Table 05 according to the prevalence of the condition scoliosis, it was found that no statistically significant differences between genders are present, but there is differences between the age groups. 
Therefore Table 05 shows the percentage of frequency data relative and accumulated in this segment. In men who have been diagnosed (12.0\%) were absent from postural deviation, (13.3\%) have simple right thoracic scoliosis, (9.3\%) simple scoliosis left thoracic, (7.3\%) with simple left lumbar scoliosis, (4.7\%) left and right thoracic "S" curve scoliosis ,(3.3\%) right and left lumbar "S" curve scoliosis.

Table 06. cumulative frequency, relative percentage and cumulative percentage analysis of disease-scoliosis for females $(\mathbf{N}=75)$.

\begin{tabular}{ccccc}
\hline Gender & Segments/Plan & Freq. $\mathbf{N}=\mathbf{7 5}$ & \% Relative & \% Cumulative \\
\hline & & & & \\
& Simple Thorac. Right & 26 & 17,3 & 26 \\
Fem. & Simple Thorac. Left & 30 & 20,0 & 56 \\
& Thorac. S-shape - R/L & 12 & 8,0 & 68 \\
& Lumb. S-shape - R/L & 07 & 4,7 & 75 \\
& Total & 75 & 50,0 & \\
& & & & \\
\hline
\end{tabular}

*Freq. $=$ Frequency $-* \mathrm{~N}=\mathrm{Quantity}$

Source: research 2014

According to (Table 06) the results found in women was that (17.3\%) have simple right thoracic scoliosis (20.0\%) simple left thoracic scoliosis (8.0\%) with right and left thoracic scoliosis with simple bending in "S", (4.7\%) with right and left lumbar scoliosis with simple curvature "S".

Table 07: Impact of BMI rating on cardiac risk in both Genres. N (150).

\begin{tabular}{c|cccc}
\hline Classification (BMI) & \multicolumn{3}{c}{ Masculine / n (75) } & \multicolumn{1}{c}{ Feminine / n (75) } \\
\hline & N* & \%** & $\mathbf{N}^{*}$ & \%** \\
Low weight & 28 & 18,7 & 21 & 14,0 \\
Normal & 22 & 14,7 & 12 & 8,0 \\
Overweight & 15 & 10,0 & 28 & 18,7 \\
Obesity & 10 & 6,7 & 14 & 9,3 \\
Total & 75 & 50,0 & 75 & 50,0 \\
\hline
\end{tabular}

$* \mathrm{~N}-$ Quantity - **\% Percentual.

Source: research 2014 
Looking at Table 07 , it is observed that the 75 males analyzed only (18.7\%) were classified as Low weight (14.7\%) with normal weight. Overweight is observed coming from the next analyzed values: $(10.0 \%)$ of overweight, $(6.7 \%)$ Obesity, a total of $(50.0 \%)$ of the research sample.

As for the 75 people of feminine gender surveyed, (14.0\%) were classified as Low weight $(8.0 \%)$ with normal weight. Overweight is observed coming from the next analyzed values: $(18.7 \%)$ of overweight, $(9.3 \%)$ Obesity, a total of $(50.0 \%)$ of the remaining sample.

Table 08: WHR rating Impact on cardiac risk in both Genres. N (150).

\begin{tabular}{ccccc}
\hline Classification (WHR) & \multicolumn{2}{c}{ Masculine / n (75) } & \multicolumn{2}{c}{ Feminine / n (75) } \\
\hline & $\mathbf{N}^{*}$ & $\mathbf{\%}^{* *}$ & $\mathbf{N}^{*}$ & $\mathbf{\%}^{* *}$ \\
Low risk & & & & \\
Moderate risk & 35 & 23,3 & 40 & 26,7 \\
High risk & 20 & 13,3 & 22 & 14,7 \\
Very high risk & 16 & 10,7 & 08 & 5,3 \\
Total & 04 & 2,7 & 05 & 3,3 \\
& 75 & 50,0 & 75 & 50,0 \\
\hline
\end{tabular}

$* \mathrm{~N}-$ Quantity - **\% Percentual.

Source: research 2014

Table 08 describes the rating values for WHR related to the evaluation of the prevalence of overweight in both sexes, showing the percentage number of WHR and sex of individuals present in certain qualifying areas.

It was found that $(23.3 \%)$ of males $(n=35)$ and $(26.7 \%)$ female group $(n=40)$ are present in the qualifying range of low risk $(13.3 \%)$ men $(\mathrm{n}=20)$ and $(14.7 \%)$ of women $(\mathrm{n}=$ $22)$ are classified as moderate risk $(10.7 \%)$ of men $(n=16)$ and $(5.3 \%)$ of women $(n=08)$ are graded in the high risk zone and the end $(2.7 \%)$ men $(n=04)$ and $(3.3 \%)$ of women $(n=$ $05)$ are ranked in the range of very high risk, representing through these values $(50.0 \%)$ for males and $(50.0 \%)$ of the total sample components for this classification. 


\section{Discution}

In this study it was found that most of the subjects showed morphological changes in body segments. Tribastone cites psychomotor disturbances, postural habits (65.5\% of cases), the paramorphisms (26.5\%) and dysmorphisms (2.5\%) as the main morphological changes.

With the population increase of the academies, it was observed that the main purpose of the practice is the aesthetic factor, and in this quest, little is worked regarding the muscle reorganization.

It was diagnosed that the prevalence of changes related to postural habits are larger than others. However, there was no case that exceed the normal morphological limits, characterizing pathologies (paramorphisms and dysmorphisms).

Postural changes can have many causes in their development, such as a congenital malformation of bones, muscle paralysis or spasticity, pressures, and deformations in the weight-bearing and maladaptive shoes as the positioning of the feet, or the joining of one or more of these factors. In addition, physical inactivity, actually present in $100 \%$ of the sample, can be one of the factors that contribute to the installation of these types of changes.

As for the feet, the discrepancy between men and women, as evidenced in this study, with high prevalence of Abduct feet for males and symmetrical for women, finds corroboration in other studies of the area, indicating a need for more research. Regarding the knees, Bruschini and Neri describe that females are more prone to valgus knee due to higher bitrocanteric diameter when compared to males, which is more likely to varus, by contrast factor.

In both sexes the collapse of the internal plantar arch (flat feet), stood out as one of the most frequent changes of factors in this study and mostly associated with knee valgus.

Bruschini and Neri (1995) in studies with obese found that the presence of protruding abdomen determines the anterior displacement of the center of gravity, with increased lumbar lordosis and anterior pelvic tilt (Antero version). The thoracic kyphosis increases, causing increased cervical lordosis and anterior displacement of the head.

With the evolution of the situation, excessive shortenings and stretches can appear that in combination with the anterior tilt of the pelvis will cause internal rotation of the hips and appearance of valgus knees and flat feet. Some of these associations were also found in this study, not only obese, but also for people with overweight or weight within normal limits. 
Relating these results, it can be said that the postural changes did not affect relevantly the changes found, since the most individuals surveyed fall within the normal rating for the prevalence of overweight parameters. However individuals lying above the body weight, may be suffering because of excess weight, exercising forms in segments and analyzed plans.

These risk values observed in the results above could be related considerably due to the age at which the sample is located. Since the higher the age, the higher cardiovascular risk caused by obesity, older age more likely to be obese; the elderly over the years lose a lot of muscle mass and accumulate higher amounts of body fat, especially in the abdominal region (Nahas, 2003).

\section{Conclusions}

According to the sampling and objectives outlined it can be concluded that: there was no values of correlations that indicate associations between postural changes, which are presented inversely proportional these when analyzed by gender, both globular and the protruded are mostly found in male.

Changes related to lower limb focus on feet valgus and Abduct and valgus knees. With regard to the Tales' triangle, the concavity is more marked for the right and the most prevalent thoracic scoliosis is simple.

It also concludes that the body mass index method (BMI) and Waist-Hip Ratio (WHR) used in this study is a simple anthropometric indicator, which helps to identify certain diseases and therefore concluded, with the data analyzed, a considerable relationship between health risk and overweight for both sexes, showing a warning to overweight and chronic diseases.

The diagnostic evaluation in the gyms for exercise prescription program is able to find different body changes with little difference between age and gender.

\section{References}

American College of Sports Medicine (2003). Diretrizes do ACMS para os Testes de Esforço e sua Prescrição. Rio de Janeiro: Guanabara. 
Bruschini, S. (1998). Pé plano postural. In: Bruschini S. (ed.). Ortopedia pediátrica. São Paulo, Atheneu.

Bruschini, S., Nery, C.A.S. (1995). Aspectos ortopédicos da obesidade na infância e adolescência. In: Fisberg M. (ed.). Obesidade na infância e adolescência. São Paulo: Fundação BYK (p.105-25).

Ellis, K.J. Human body composition: in vivo methods. (2000). Rev Phisiol., 80(2), 649-80.

Heyward, V.H, Stolarczyk LM. (2000). Avaliação da composição corporal aplicada. São Paulo: Manole.

Nahas, M. V. (2003). Atividade física, saúde e qualidade de vida: conceitos e sugestões para um estilo de vida ativo. (3th ed.). Londrina: Midiograf.

Pieron, M. (2004). Estilo de vida, prática de atividades físicas e esportivas, qualidade de vida. Fit Perfor J, (p. 10-17).

Tribastone, F. (2001). Tratado de Exercícios Corretivos Aplicados a Reeducação Motora Postural. São Paulo: Manole.

Received: 12/08/2016.

Accepted: 05/10/2016

\section{How to cite this article (APA format):}

Maciel, João P.S., Souza, Thiago C., Dias, Raphael R., Silva, Elizabeth A. (2016). The importance of prescribing exercise programs in gyms. Amadeus International Multidisciplinary Journal, 1(1), 3-13. 